\title{
Hepatitis A Virus Prevalence among Healthcare Students and Profissionals of Federal University of Bahia, Brazil
}

\author{
Andrade J 1,4,8, Freire SM2,5,6-8, Macedo LS ${ }^{1,6,8}$, \\ de Souza Campos $\mathrm{M}^{2,3,5}$, Rego MAV ${ }^{1}$, Schaer \\ $\mathbf{R E}^{2,6}$, Meyer $\mathbf{R}^{2,5,6,8,9}$, Simoes J M ${ }^{2,6}$, Parana $\mathrm{R}^{1,3,8}$, \\ Schinoni MI'-3,8* \\ ${ }^{1}$ Faculty of Medicine of Bahia, Brazil \\ ${ }^{2}$ Institute of Health Sciences-Federal University of Bahia, \\ Brazil \\ ${ }^{3}$ University Hospital Professor Edgar Santos, Brazil \\ ${ }^{4}$ Reference Center for Special Immunobiologicals, Brazil \\ ${ }^{5}$ Graduate Program in Interactive Processes of Organs \\ and Systems, Brazil \\ ${ }^{6}$ Laboratory of Immunology and Molecular Biology-ICS- \\ UFBA, Brazil \\ ${ }^{7}$ Bahiana School of Medicine and Public Health, Brazil \\ ${ }^{8} \mathrm{CNPq}$ Researcher, Brazil \\ *Corresponding author: Maria Isabel Schinoni, \\ University Hospital Professor Edgar Santos, Institute \\ of Health Sciences-Federal University of Bahia, Av, \\ Prnicesa Isabel 86 Ap 1701, Barra Avenida, CEP 401400o, \\ Salvador, Brazil
}

Received: December 01, 2020; Accepted: January 11, 2021; Published: January 18, 2021

\begin{abstract}
Introduction: Hepatitis A Virus (HAV) is a hepatotrophic virus with oral-fecal transmission. Occupational exposition to the virus is not common in the health practice and this way of contagious is not considered as a risk of infection. Adults have more probability to have fulminate clinical manifestations and in Brazil, the most of population older than 20 years have had contact with this virus. Aim: to study the prevalence of antibodies anti A virus (IgGHAV) in students (group 1 ) and professionals (group 2) of the health area of the Federal University of Bahia (UFBA). Methods: was studied IgGHAV in 335 seras from volunteers who had completed an epidemiological questionnaire. Results: Antibodies IgGHAV+ in $56,1 \%$ of the sample and $43,9 \%$ of the individuals were susceptible to the infection. $94,4 \%$ of the professional had $\operatorname{lgGHAV}{ }^{+}$and $48,8 \%$ of the students had $\operatorname{lgGHAV} V^{+}(p=0,000)$. There was an association between professional category and history of exposition to biological material $(p=0,0017)$. There was not association between IgGHAV ${ }^{+}$and history of exposition to biological material. This result could show the environment and occupational exposition to this virus. The more prevalence of IgGHAV titers in the professional individuals who were older shows the spread of the infection life through. Conclusion: this study showed that $43,9 \%$ of the individual who start to work in contact with biological material are susceptible to the hepatitis $\mathrm{A}$ infection, this generate an new epidemiological reconsideration about the practice of vaccination in this special population in Brazil.
\end{abstract}

Keywords: Hepatitis A; Health personnel; Prevalence; Vacination

\section{Abbreviations}

HAV: Hepatitis A Virus; HDI: Human Development Index; IBGE: Brazilian Institute of Geography and Statistics; UFBA: Federal University of Bahia; ICS: Institute of Health Sciences; SMURB: Rubens Brasil University Medical Service; CRIE-UFBA: Reference Center for Special Immunobiologicals; STD: Sexually Transmitted Disease

\section{Introduction}

Infection with the hepatitis A virus (HAV) occurs worldwide, affecting approximately 1.4 million people per year [1]. Highly endemic regions are recognized, especially in South and Central America, Africa, the Middle East, Asia and the West Pacific coast [2]. Its prevalence is related to the low Human Development Index (HDI), due to the fact that it is transmitted via the fecal-oral route [3]. In these areas, epidemics are uncommon, since the adult population, where the disease manifests itself more severely, already has antibodies acquired in childhood due to early exposure to the virus [1]. According to the demographic census conducted in 2000 by the Brazilian Institute of Geography and Statistics (IBGE), more than half of the Brazilian municipalities do not have a sewage system (58.4\%) [4], a fact that is directly related to the high prevalence of HAV. According to the demographic census conducted in 2010, $61.8 \%$ of Brazilian households were classified as "adequate" sanitation in a classification that involved the quality of the sewage system, water supply and waste disposal [5]. In South and Central America, according to population data from 1990, 162,000 new cases were estimated to occur each year [1]. In addition, a study carried out between 2001 and 2002 in nine centers in Latin America showed that hepatitis A was the main etiological agent of acute liver failure [6]. In Brazil, the Pan American Health Organization estimates that there are 130 new cases per year for every 100 thousand inhabitants and that more than $90 \%$ of the population over 20 years old has already had exposure to HAV [7]. Despite improvements in sanitation conditions, there is still a high circulation of HAV in Brazil, however population studies on the prevalence of HAV infection have been scarce in the country after the improvement in HDI over the past two decades [8]. The objective of this work was to study the seroprevalence of HAV in students and health professionals linked to the Federal University of Bahia (UFBA) and who work in a high-complexity hospital, therefore with a high risk of professional exposure.

\section{Materials and Methods}

It was a cross-sectional study with a sample of students and health professionals at UFBA. Students from medical, nursing and pharmacy courses participated, as well as professionals from the teaching units of the medical, nursing, pharmacy and multidisciplinary teaching units of the Institute of Health Sciences (ICS). The professional category included health professors, laboratory assistant technicians, nursing assistant technicians and technicians and employees responsible for hygiene, in pharmacy, medicine, nursing, physiotherapy and speech therapy and biology courses. The study excluded individuals from the administrative area without technical or higher education in
Austin Hepatol - Volume 6 Issue 1 - 2021

Submit your Manuscript | www.austinpublishing group.com

Schinoni et al. () All rights are reserved
Citation: Andrade J, Freire SM, Macedo LS, de Souza Campos M, Rego MAV, Schaer RE, et al. Hepatitis A Virus Prevalence among Healthcare Students and Profissionals of Federal University of Bahia, Brazil. Austin Hepatol. 2021; 6(1): 1014 
health. Report of exposure to biological material was self-reported by the participants as any type of direct contact with at least one of the following biological materials: blood, saliva, pus, urine, feces, sputum, vomit, tissue, CSF. This study used the database obtained in the institutional vaccination campaign against Hepatitis B, carried out during 2007, which had the active participation and support of the boards of the teaching units of UFBA, of the Rubens Brasil Medical Service (SMURB) and the Reference Center for Special Immunobiologicals (CRIE-UFBA). During the campaign, the volunteers answered a clinical epidemiological survey and had their blood collected for analysis of the serological profile with the AntiHAV IgG markers. The tests were performed by automation using the commercial ARCHITECT HAVAb IgG Reagent Kit for qualitative determination of the IgG antibody against HAV. The device used was Architect. The clinical-epidemiological interview consisted of a questionnaire with socio-demographic variables such as age, gender, phenotypic "racial" self-classification, marital status and UFBA. For greater convenience, the questionnaire was divided into two parts. The first, applied by previously trained interviewers and the second, with questions of a private nature, which was self-applicable, which provided greater privacy to the participants.

The groups were categorized for analysis as follows:

1) Students $x$ Professionals

2) Seropositive $x$ Seronegative

3) Exposed to biological material $x$ Not exposed

The data were analyzed using the statistical software SPSS version 13.0. Descriptive analysis of the data was performed and the Prevalence Ratios (PR) and respective 95\% confidence intervals were calculated. The Chi-square test $\left(\chi^{2}\right)$ was applied to test the hypothesis of association between dichotomous variables. Stratified analysis was performed to control the average age and reports of exposure to biological material among students and professionals. The results were considered statistically significant with a value of $p<0.05$ or the null value was outside the confidence interval. The project was approved by the Research Ethics Committee of the Bahiana Foundation for the Development of Sciences, opinion n' 20/2004 and 36/2004.

\section{Results}

335 blood samples were collected for analysis, 83.9\% (281/335) students and $16.1 \%(54 / 335)$ professionals. Socio-demographic data can be found in (Table $1 \&$ Graph 1). Among all participants, 69.9\% $(234 / 335)$ were women while $30.1 \%(101 / 335)$ were men. The average age of the sample was 25.44 years. The most prevalent ethnic group was "mulattos", with $55.5 \%$ of the total, followed by "whites" with $27.2 \%$, "blacks" with $15.2 \%$, "indigenous" with $1.5 \%$ and "oriental" with $0.6 \%$ of the total number of volunteers. There was no significant difference in the prevalence of HAV between different ethnicities. Among the individuals evaluated of the total sample, 56.1\% (188/335) presented IgG antibody positive for HAV and 43.9\% (147/335) were negative. Among the professionals $(\mathrm{n}=54)$ working in health education and assistance, $94.4 \%(51 / 54)$ were seropositive, while in students $(\mathrm{n}=281)$, this seropositivity was $48.8 \%(137 / 281)$. This seropositivity relationship within the category proved to be relevant $(\mathrm{p}=0.000)$ for the professional category, (Table 2). When evaluating the entire
Table 1: Epidemiological profile of the studied population.

\begin{tabular}{|c|c|c|c|c|c|c|c|}
\hline \multirow[t]{4}{*}{ Variables } & & \multicolumn{4}{|c|}{ Category } & & \\
\hline & & \multirow{2}{*}{\multicolumn{2}{|c|}{$\begin{array}{c}\text { Student } \\
n=281\end{array}$}} & \multirow{2}{*}{\multicolumn{2}{|c|}{$\begin{array}{c}\text { Professional } \\
n=54\end{array}$}} & \multicolumn{2}{|c|}{ Total } \\
\hline & & & & & & $n=33$ & \\
\hline & & $N$ & $\%$ & $\mathrm{n}$ & $\%$ & $\mathrm{n}$ & $\%$ \\
\hline \multirow{2}{*}{ Genre } & Female & 194 & 69 & 40 & 74,1 & 23468,8 & 69,9 \\
\hline & Male & 87 & 31 & 14 & 25,9 & 101 & 30,1 \\
\hline \multirow{4}{*}{ Capacity } & Medicine & 97 & 34,5 & 5 & 9,3 & 102 & 30,4 \\
\hline & Nursing & 107 & 38,1 & 11 & 20,4 & 118 & 35,2 \\
\hline & Pharmacy & 77 & 27,4 & 24 & 44,4 & 101 & 30,2 \\
\hline & ICS & 0 & 0 & 14 & 25,9 & 14 & 4,2 \\
\hline \multirow{3}{*}{ Age } & $\begin{array}{l}\text { Minimum and } \\
\text { maximum }\end{array}$ & \multicolumn{2}{|c|}{17 e 48} & \multicolumn{2}{|c|}{20 e 66} & \multicolumn{2}{|c|}{17 e 66} \\
\hline & Average & \multicolumn{2}{|c|}{22,21} & \multicolumn{2}{|c|}{42,28} & \multicolumn{2}{|c|}{25,44} \\
\hline & Median & \multicolumn{2}{|c|}{22} & \multicolumn{2}{|c|}{41,5} & \multicolumn{2}{|l|}{22} \\
\hline
\end{tabular}

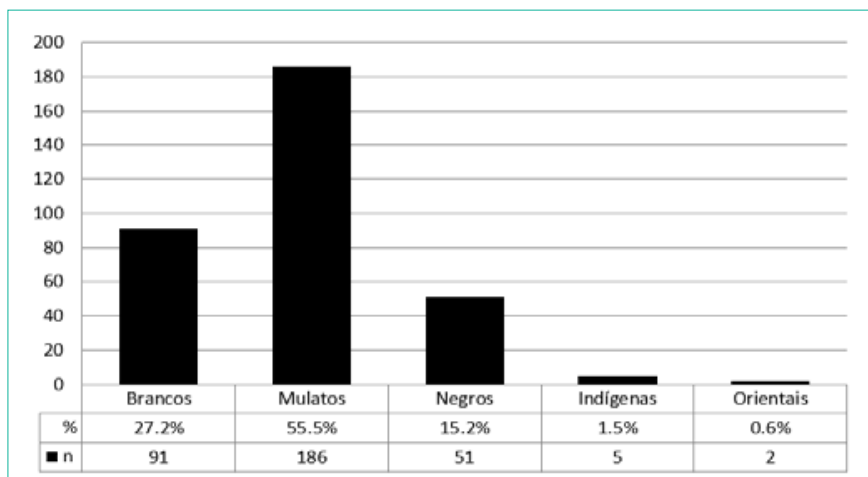

Graphic 1: Self-Referenced Ethnic Profile of the Studied Population.

Table 2: HAV serology among the analyzed categories.

\begin{tabular}{|c|c|c|c|c|c|c|}
\hline & & & \multicolumn{2}{|c|}{ HAV serology } & \multirow[t]{2}{*}{ Total } & \multirow[t]{2}{*}{ RP (IC 95\%) } \\
\hline & & & Positive & Negative & & \\
\hline \multirow{2}{*}{ Category } & \multirow{2}{*}{ Student } & $\mathrm{N}$ & 137 & 144 & 281 & \\
\hline & & $\%$ & $48,8 \%$ & $51,2 \%$ & $100,0 \%$ & 1,93 \\
\hline & & & & & & $(1,56-2,38)$ \\
\hline & \multirow{2}{*}{ Professional } & $\mathrm{N}$ & 51 & 3 & 54 & $p=0,000$ \\
\hline & & $\%$ & $94,4 \%$ & $5,6 \%$ & $100,0 \%$ & \\
\hline \multirow{2}{*}{\multicolumn{2}{|c|}{ Total }} & $\mathrm{N}$ & 188 & 147 & 335 & \\
\hline & & $\%$ & $56,1 \%$ & $43,9 \%$ & $100,0 \%$ & \\
\hline
\end{tabular}

sample, the stratified analysis of seropositivity by age indicated that older individuals had higher seropositivity for HAV, (Table 3). In addition, the Mann-Whitney statistical test revealed that the median age of individuals with a report of exposure biological material was significantly higher than the median age of those not exposed to these materials. When analyzing the average age in the category of those exposed to biological material, there was a higher average age among professionals $(40.78+/-11.52)$, when compared to students (22.74+/-3.07) also with report of exposure to biological waste. In the non-exposed category, similar results were observed between these two classes, professionals $(44.88+/-11.24)$ and students $(21.64+/$ $3.44)$. When analyzed the presence of exposure to biological material 
Table 3: Serology for HAV in different age groups.

\begin{tabular}{|c|c|c|c|c|c|}
\hline & & & \multicolumn{2}{|c|}{ HAV serology } & \multirow{2}{*}{ Total } \\
\hline & & & Positive & Negative & \\
\hline \multirow{12}{*}{ Age } & \multirow{2}{*}{ up to 19 years } & $\mathrm{N}$ & 17 & 23 & 40 \\
\hline & & $\%$ & $42,5 \%$ & $57,5 \%$ & $100,0 \%$ \\
\hline & \multirow{2}{*}{ 20-22 years } & $\mathrm{N}$ & 65 & 82 & 147 \\
\hline & & $\%$ & $44,2 \%$ & $55,8 \%$ & $100,0 \%$ \\
\hline & \multirow{2}{*}{$23-25$ years } & $\mathrm{N}$ & 35 & 33 & 68 \\
\hline & & $\%$ & $51,5 \%$ & $48,5 \%$ & $100,0 \%$ \\
\hline & \multirow{2}{*}{$26-28$ years } & $\mathrm{N}$ & 17 & 5 & 22 \\
\hline & & $\%$ & $77,3 \%$ & $22,7 \%$ & $100,0 \%$ \\
\hline & \multirow{2}{*}{ 29-31 years } & $\mathrm{N}$ & 9 & 2 & 11 \\
\hline & & $\%$ & $81,8 \%$ & $18,2 \%$ & $100,0 \%$ \\
\hline & \multirow{2}{*}{$32^{+}$years } & $\mathrm{N}$ & 45 & 2 & 47 \\
\hline & & $\%$ & $95,7 \%$ & $4,3 \%$ & $100,0 \%$ \\
\hline & \multirow{2}{*}{ Total } & $\mathrm{N}$ & 188 & 147 & 335 \\
\hline & & $\%$ & $56,1 \%$ & $43,9 \%$ & $100,0 \%$ \\
\hline
\end{tabular}

${ }^{*}$ Chi-Square $=58.251$ (observe chi-square distribution below considering 5 degrees of freedom and $\alpha=0.05)$.

versus non-exposure between students and professionals, there was no age difference within each subcategory, student or professional. When HAV serology was evaluated, the presence of positive AntiHAV IgG, it was observed that age in those exposed to biological materials was not a factor that contributed to the presence of these antibodies. Direct exposure to biological material was admitted by $69.2 \%(36 / 52)$ of health professionals and 50\% (135/270) of students. There was a positive association $(\mathrm{p}=0.017)$ between reports of direct exposure to biological material and the professional category, with no positive association in the group of students, (Table 4 ). There was no statistically significant association $(\mathrm{p}=0.184)$ between reports of exposure to biological material and seropositivity for HAV, (Table 5). When the susceptibility (seronegativity to HAV) to exposure to HAV was evaluated in individuals in the health students category, it was found that among the 135 students who admitted contact with biological material, 66/135 (48.9\%) were seronegative for the anti HAV IgG. On the other hand, among professionals, despite 36 out of 52 having admitted contact with biological material, seronegativity for this marker was only found in $3 / 36$ (8.3\%). This data demonstrates that there is considerable susceptibility in the group of students with reports of exposure to biological material. When assessing sexual habits, it was observed that among all HIV-positive individuals (188/335) for HAV, 98.9\% (186/188) admitted to being heterosexual and only $1.1 \%(2 / 188)$ defined themselves as homo or bisexual. Of these HIV-positive people, $22.9 \%(43 / 188)$ had 3 or more sexual partners per year at some time in their lives; $14.4 \%$ (27/188) never or almost never used condoms in their sexual relationships; $2.7 \%$ (5/188) had sexual relations with sex workers and $7.4 \%(14 / 188)$ reported some Sexually Transmitted Disease (STD).

Among seronegative (147/335), 80.3\% (118/147) reported being heterosexual and only $1.4 \%(2 / 147)$ defined themselves as homo or bisexual. In addition, $20.4 \%(30 / 147)$ had 3 or more sexual partners in the year at one time, $11.6 \%(17 / 147)$ said they never or almost never use condoms in their sexual relationships, $0.7 \%(1 / 147)$ reported experience with a sex worker and 3.4\% (5/147) reported some STD.

\section{Discussion}

The high prevalence of mulatto participants in the evaluated sample is justified, as Salvador is one of the cities with a large percentage of Afro-descendent inhabitants (79.5\%), mainly due to African migration at the time of colonization [5]. As for the results related to the sexual behavior of the study participants, it was not possible to define an association between seropositivity and sexual exposure to HAV due to data loss. The difference in frequency of Anti-HAV IgG seropositivity observed between professionals and students reflects the age difference between these two groups, meaning greater exposure to HAV throughout life, regardless of professional practice. In our study, interestingly, greater exposure to biological material had no significant association with HIV-positive seropositivity, which strengthens the importance of exposure to this virus even in the extra-academic community. These data coincide with those of Trevisan, A. and collaborators, who, evaluating healthcare workers, specifically in the biochemistry area, in Italy, demonstrated $44.9 \%$ anti-HAV IgG seroprevalence, unrelated to biological exposure, concluding that infection with the hepatitis A virus is not a risk factor for workers in the biomedical field. In this sample, seroprevalence was also higher at older ages [9]. In our study, the group of health professionals is older, a fact that could also indicate community contact with HAV. The fact that we found a percentage of 50\% (135) of students who had a history of contact with biological material shows the risk of exposure in this population, especially if we consider that $66 / 135$ (48.9\%) of these students were susceptible to HAV, that is, they were seronegative, while in the group of professionals, of the $36 / 52(69.2 \%)$ with a history of contact with biological material, only $3 / 36(8.3 \%)$ showed susceptibility to HAV, the majority being seropositive. These results suggest that exposure to biological residues may also have a percentage of contribution to the transmission of HAV in the studied population, although without statistical significance, probably due to the small number of individuals in our sample. Evidently, health professionals have a longer time of successive exposures to biological materials, especially those with fecal-oral transmission, consequently with a higher risk of

Table 4: Contact with biological material in the different categories analyzed.

\begin{tabular}{|c|c|c|c|c|c|c|c|c|}
\hline \multirow[t]{4}{*}{ Variables } & & \multicolumn{4}{|c|}{ Category } & & & \multirow[b]{2}{*}{ RP (IC 95\%) } \\
\hline & & \multicolumn{2}{|c|}{ Student } & \multicolumn{2}{|c|}{ Professional } & \multicolumn{2}{|c|}{ Total } & \\
\hline & & \multicolumn{2}{|c|}{$\mathrm{n}=270^{*}$} & \multicolumn{2}{|c|}{$n=52^{*}$} & \multicolumn{2}{|c|}{$n=322$} & \\
\hline & & $\mathrm{N}$ & $\%$ & $\mathrm{n}$ & $\%$ & $\mathrm{n}$ & $\%$ & 1,38 \\
\hline \multirow{2}{*}{ Contact with biological material ${ }^{*}$} & Yes & 135 & 50 & 36 & 69,2 & 171 & 53,1 & $(1,06-1,80)$ \\
\hline & Not & 135 & 50 & 16 & 30,8 & 151 & 46,9 & $p=0,017$ \\
\hline
\end{tabular}

*Due to lack of completion, 13 data of this variable (contact with biological material) were lost, 11 of which were students and 2 were professionals. 
Table 5: Contact with biological material x Seropositivity.

\begin{tabular}{|c|c|c|c|c|c|c|c|c|}
\hline \multirow[t]{4}{*}{ Variables } & & \multicolumn{4}{|c|}{ HAV serology } & & & \multirow[b]{2}{*}{ RP (IC 95\%) } \\
\hline & & \multirow{2}{*}{\multicolumn{2}{|c|}{$\begin{array}{c}\text { Positive } \\
n=180^{\star}\end{array}$}} & \multirow{2}{*}{\multicolumn{2}{|c|}{$\begin{array}{c}\text { Negative } \\
n=142^{*}\end{array}$}} & \multicolumn{2}{|c|}{ Total } & \\
\hline & & & & & & \multicolumn{2}{|c|}{$n=322$} & \\
\hline & & $\mathrm{N}$ & $\%$ & $\mathrm{n}$ & $\%$ & $\mathrm{n}$ & $\%$ & 1,16 \\
\hline \multirow{2}{*}{ Contact with biological material $^{\star}$} & Yes & 102 & 56,7 & 69 & 48,6 & 171 & 53,1 & $(0,93-1,44)$ \\
\hline & Not & 78 & 43,3 & 73 & 51,4 & 151 & 46,9 & $p=0,184$ \\
\hline
\end{tabular}

*Due to lack of filling, 13 data of this variable (contact with biological material) were lost, 8 of them seropositive and 5 of seronegative.

infection. Chodick, G. and colleagues, retrospectively evaluating 26 records of hepatitis A outbreaks among health professionals and 23 seroepidemiological studies in this population in Europe, between 1975 and 2003, found that during the outbreaks, nurses constituted the largest infected group. In that same study, seroprevalence for HAV ranged from $4 \%$ in Germany to $88 \%$ in Portugal, among health professionals. The authors suggest educational measures in this population, in addition to pre-admission screening and vaccination of susceptible individuals [10]. In a survey carried out in four Brazilian capitals (Manaus, Fortaleza, Porto Alegre and Rio de Janeiro), the mean HAV seroprevalence was $64.7 \%$ in the general population [11]. In a study carried out with the support of the Ministry of Health in the Brazilian capitals of the Northeast, Midwest and Federal District, HAV seroprevalence ranging from $32.26 \%$ to $66.67 \%$ was found in individuals aged 5 to 19 years [12]. Thus, when we compare the results of our study (anti-HAV IgG seropositivity of $56.1 \%$ in the age group between 17 and 66 years) with the seroprevalence of Anti HAV IgG in the population of the capitals of the Northeast, the region with the worst HDI in the country (13), we observed that in this population study, involving individuals from all social strata, $41.4 \%$ showed seropositivity for anti HAV IgG still in the age group of 5 to 9 years. Seroprevalence for anti HAV IgG increased to $57.4 \%$ in the age group between 10 and 19 years old [14], even so, much lower than expected. This factor can be explained by the basic sanitation policies carried out in recent years in all Brazilian capitals. The Bahia Azul Program, implemented in 1997, improved the sanitary condition of some areas of the city of Salvador. Research has shown a significant increase in the population served by the general sewage network, with a variation from 24\% in 1991 (before Bahia Azul) to $74 \%$ in 2000 (after Bahia Azul). However, there is still an important difference between neighborhoods in the city, since according to IBGE, in the year 2000, about $70 \%$ of the neighborhoods were covered by the population with a general sewage system above $80 \%$, while around $30 \%$ of neighborhoods had coverage below $80 \%$ [15]. On the other hand, a study carried out in 2000 evaluated the functioning of the sewage network in operation in 23 micro-areas covered by the Bahia Azul Program in the city of Salvador, classifying 10 micro-areas as a bad condition; regular condition in 10 micro-areas and good condition in only 3 micro-areas [15]. In addition, a study of bacteriological and physical-chemical analyzes of 310 water samples in the years 1997 and 2003 (before and after the implementation of Bahia Azul) showed that the quality of the water supplied continues not to meet the potability standards, worsening in the households due to improper handling of consumers [16]. Despite the health improvements mentioned above, these data reinforce the possible exposure of the general population to the hepatitis A virus. Sanitary improvements are reflected in the change in the epidemiological pattern of HAV recently observed throughout South America, from high to medium endemicity. In Brazil, this is more evident in the south and southeast regions. Outbreaks of hepatitis A have been recorded in public schools and daycare centers in Brazil, affecting susceptible children, mainly under 10 years old, regardless of socioeconomic level [17]. According to preliminary data from the IBGE demographic census conducted in 2010, there was a significant improvement in sanitation conditions in Brazil, with an increase in the number of households with adequate sanitation from $45.3 \%$ in 1991 to $61.8 \%$ in 2010 [5]. This reality can vary enormously according to the HDI of each municipality in the country, as well as the social extract of the studied population. We know that Brazil is heterogeneous in these aspects. For example, when analyzing Brazil as a whole, $61.8 \%$ of households have running water, a sewage system and garbage collection. However, if we analyze their regions separately, sanitation conditions are adequate in $90.7 \%$ of the municipalities with more than 500,000 inhabitants in southeastern Brazil, while only $66.6 \%$ of the municipalities with more than 500,000 inhabitants in northeastern Brazil and $51.7 \%$ of the municipalities with more than 500,000 inhabitants in the northern region have adequate conditions [5]. In the rural zone of the semi-arid region of the Northeast, in the interior of Bahia, the prevalence of HAV of 83.3\%, among adults and children, denotes the epidemiological heterogeneity of HAV in Brazil, probably associated with the worst HDI and the worst health conditions, as it happens in rural communities in the northeast of the country [13]. Other studies carried out in different regions report conflicting results. In Rio de Janeiro, 24\% of children aged 1 to 10 years were seropositive for anti-HAV IgG [18]. In São Paulo, 28.09\% in the age group between $5-9$ years and from 35.81 to $56.16 \%$ for 10 to 17 years [19], reflecting the high prevalence in Latin America, which varies from 55 to $89 \%$ [20]. The population evaluated in our study was composed entirely of adults. A large percentage (43.9\%) of these adults were susceptible to HAV, particularly in the age group where the morbidity and mortality from hepatitis A becomes more expressive [21]. This aspect reinforces the need for emerging countries like Brazil to reevaluate their vaccination policies, even if primarily in populations at risk. We also need population data to assess the cost/ benefit of including the hepatitis A vaccine in the mandatory vaccination schedule. Some cost-benefit studies strongly suggest that it is advantageous to adopt vaccination especially in areas of high incidence in Brazil, such as in the State of Parana [22]. In developed countries, this same type of study helped to implement routine vaccination in the general population, as in the United States [23]. In Brazil, vaccination against Hepatitis $\mathrm{A}$ is not on the calendar of mandatory immunizations in the public service. There is also no specific recommendation for HAV vaccination by the health professional in the different Brazilian guides [7,24]. However, in 
countries where the vaccination scheme is broader than in Brazil, such as the United States and Israel, vaccination against HAV is already routinely recommended, thus contemplating health students $[2,25]$. Prevention of HAV infection is important in the adult age group, depending on the severity of the disease in this group. Most cases of acute fulminant hepatitis secondary to HAV occur in individuals aged between 21 and 72 years (mean age: 48 years), according to American data [26]. A Brazilian study evaluating the age group of 3-62 years (mean age of 22.5 years) showed that the highest incidence of acute fulminant hepatitis was found between 21 and 30 years [27]. Our study showed that occupational exposure to HAV in the health area is neglected in the country, and vaccination is not recommended for health professionals [17]. In the evaluated population, $43.9 \%$ of adult individuals who initiate professional training activities or who perform functions in a health institution are susceptible to HAV, therefore with a high risk of developing severe forms of the disease. These data reinforce the importance of the Brazilian health authorities to reassess the need to expand the Brazilian vaccination calendar, introducing the HAV vaccine into the basic vaccination schedule as a routine practice for the general population in Brazil. In this way, health professionals would benefit, since exposure to biological material alone does not justify HAV seropositivity in this population and environmental exposure occurs depending on the different prevalence of HAV in different regions of the country.

\section{Thanks}

The project had strategic and financial support from professors from various units of UFBA, from the Postgraduate Program in Immunology (PPGIm), Postgraduate Support Program from the Coordination for the Improvement of Higher Education Personnel (PROAP-CAPES), Council National Scientific and Technological Development $(\mathrm{CNPq})$, Laboratory of Immunology and Molecular Biology (Labimuno), CRIE / UFBA, Ministry of Health, Bahia State Health Secretariat (SESAB), Salvador Municipal Health Secretariat (SMS) and leaders UFBA units.

\section{References}

1. World Health Organization. Department of Communicable Disease Surveillance and Response. WHO/CDS/CSR/EDC/2000.7.

2. Center for Disease Control and Prevention (CDC). Hepatitis A. MMWR. 2009 7: $85-97$

3. Wasley A, Grydal S, Gallagher K. Surveillance for acute viral hepatitis-United States, 2006. MMWR Surveill Summ. 2008; 57:1-24

4. Brazilian Institute of Geography and Statistics -IBGE. Demographic Census. 2000.

5. Brazilian Institute of Geography and Statistics-IBGE. Municipal Social Indicators-An analysis of the results of the 2010 Population Census universe.

6. Ciocca M, Moreira-Silva SF. Hepatitis A. as an Etiologic Agent of Acute Liver failure in Latin America. The Pediatric Infectious Disease Journal. 2007; 26: 711-715

7. Brazil. Ministry of Health. Secretariat of Health Surveillance. Department of Epidemiological Surveillance. Epidemiological Surveillance Guide/Ministry of Health, Secretariat of Health Surveillance, Department of Epidemiological Surveillance- $6^{\text {th }}$ Ed. - Brasília: Ministry of Health. 2007.

8. Ministry of Health. Secretariat of Health Surveillance. Report of activities developed in 2006 - Summary. January. 2007.

9. Trevisan A, Stocco E, Fanelli G, Bicciato F, Paruzzolo P. Seroprevalence of hepatitis A markers in subjects exposed to biological risk. International
Archives of Occupational and Environmental Health. 1999; 72: 125-127.

10. Chodick G, Ashkenazi S, Lerman Y. The risk of hepatitis A infection among healthcare workers: a review of reported outbreaks and sero-epidemiologic studies. Journal of Hospital Infection. 2006; 62: 414-420.

11. Clemens SAC, Fonseca JC, Azevedo T, Cavalcanti A, Silveira TR, Castilho $M C$, et al. Seroprevalence for hepatitis A and hepatitis B in four centers in Brazil. Rev Soc Bras Med Trop Jan/Feb. 2000; 33: 1-10.

12. Brazil. Ministry of Health. Secretariat of Health Surveillance. Department of Epidemiological Surveillance. Infectious and parasitic diseases: pocket guide/Ministry of Health, Secretariat of Health Surveillance, Department of Epidemiological Surveillance- $7^{\text {th }}$ Ed Rev Brasilia: Ministry of Health. 2008.

13. Almeida D, Neto JT, Vitvitski L, Almeida A, Mello C, Santana D, et al. Serological Markers of Hepatitis A, B and C Viruses in Rural Communities of the Semiarid Brazilian Northeast. The Brazilian Journal of Infectious Diseases. 2006; 10: 317-321.

14. Alencar Ximenes RA, Martelli CMT, Merchan-Hamann E, Montarroyos UR, Braga MC, Lima MLC, et al. Multilevel analysis of hepatitis A infection in children and adolescents: a household survey in the Northeast and Centralwest regions of Brazil. International Journal of Epidemiology. 2008; 37: 852861.

15. Lima AMC. Sanitary-environmental indicators: classification of sewage basins and micro-areas in the city of Salvador-Bahia. 2008. $115 \mathrm{f}$. Dissertation (Master in Health, Environment and Work)-Faculty of Medicine of Bahia, Federal University of Bahia, Salvador. 2008.

16. Alvares MLP, Borja PC, Moraes LRS, Dias MC. Evaluation of the interventions of the bahia azul program in the quality of the water distributed by the water supply system in the city of Salvador, Bahia, Brazil. In: AIDIS - Forging the Environment We Share. San Juan, AIDIS. 2004: 1-16.

17. Stained Glass CL, Souto FJD, Gaspar AMC. Changing Epidemiology of hepatitis $A$ in Brazil: reassessing immunization policy. Journal of Viral Hepatitis. 2008; 15: 22-25.

18. Braga RCC, Valencia LIO, Medronho RA, Escosteguy CC. Estimation of risk areas for hepatitis A Cad Saude Publica, Rio de Janeiro. 2008; 24: 17431752.

19. Focaccia R, da Conceicao OJG, Junior HS, Sabino E, Bassit L, Nitrini DR, et al. Estimated prevalence of viral hepatitis in the general population of the Municipality of São Paulo, measured by a serologic survey of a stratified, randomized and residence-based population. The Brazilian Journal of Infectious Diseases, 1998; 2: 269-284.

20. Tapia-Conyer R, Santos JI, Cavalcanti AM, Urdaneta E, Rivera L, Manutencaoola A, et al. Hepatitis A in Latin America: a changing epidemiologic pattern. Am J Trop Med Hyg. 1999; 61: 825-829.

21. Lednar WM, Lemon SM, Kirkpatrick JW, Redfield RR, Fields ML, Kelley PW. Frequency of illness associated with epidemic hepatitis $A$ virus infection in adults. Am J Epidemiol. 1985; 122: 226-233.

22. Zahdi MR, Junior IM, Maluf EMCP. Hepatitis A: The costs and benefits of the disease prevention by vaccine, Paraná, Brazil. The Brazilian Journal of Infectious Diseases, 2009; 13: 257-261.

23. Rein DB, Hicks KA, Wirth KE, Billah K, Finelli L, Fiore AE, et al. Costeffectiveness of routine childhood vaccination for hepatitis $A$ in the United States. Pediatrics. 2007; 119: e12-e21.

24. Brazil. Ministry of Health. Secretariat of Health Surveillance. Department of Epidemiological Surveillance. Manual of Reference Centers for Special Immunobiologicals. Brasília/Ministry of Health. 2006: 188.

25. Dagan R, Leventhal A, Anis E, Slater P, Ashur Y, Shouval D. Incidence of hepatitis $A$ in Israel following universal immunization of toddlers. JAMA. 2005; 294: 202-210.

26. Taylor RM, Davern T, Munoz S, Han SH, McGuire B, Larson AM, et al. Fulminant Hepatitis A virus infection in the United States: incidence, prognosis and outcomes. Hepatology. 2006; 44: 1589-1597.

27. Da Silva LC, Madruga CLA. Peculiar aspects and natural history of hepatitis A. In: Da Silva LC, editor. Acute and chronic hepatitis. $3^{\text {rd }}$ ed. São Paulo: Sarvier. 2003; 184-190. 